\title{
Grape skin and loquat leaf extracts and acai puree have potent anti-atherosclerotic and anti-diabetic activity in vitro and in vivo in hypercholesterolemic zebrafish
}

\author{
JAE-YONG KIM ${ }^{1,4 *}$, JOO-HEON HONG ${ }^{2 *}$, HEE KYOUNG JUNG ${ }^{3}$, \\ YOO SEOK JEONG ${ }^{3}$ and KYUNG-HYUN CHO ${ }^{1,4}$
}

\begin{abstract}
${ }^{1}$ School of Biotechnology, Yeungnam University, Gyeongsan 712-749; ${ }^{2}$ Department of Food Science and Technology, Catholic University of Daegu, Gyeongsangbukdo 712-702; ${ }^{3}$ Bio Industry Center, Daegu Technopark, Daegu 704-701;

${ }^{4}$ Research Institute of Protein Sensor, Yeungnam University, Gyeongsan 712-749, Republic of Korea
\end{abstract}

Received January 31, 2012; Accepted March 30, 2012

DOI: $10.3892 / \mathrm{ijmm} .2012 .1045$

\begin{abstract}
Three major sources of flavonoids and phenolic compounds, which are commonly used in food industry, namely loquat leaf (LL), grape skin (GS) and acai puree, were tested in regard to their potential anti-atherosclerotic and anti-diabetic activity. The compounds were evaluated by in vitro antioxidant assay using a macrophage model and for in vivo hypolipidemic activity using zebrafish. In assays in vitro, all extracts demonstrated potent ferric ion reductive capacity, radical-scavenging activity and inhibition of lowdensity lipoprotein (LDL) oxidation at a final concentration of $0.1 \mathrm{mg} / \mathrm{ml}$. Extracts could also abrogate fructose-mediated protein glycation and mildly inhibit cholesteryl ester transfer protein (CETP). Cellular uptake of oxidized or acetylated LDL into macrophages was inhibited by acai treatment (final concentration, $0.1 \mathrm{mg} / \mathrm{ml}$ ) and moderately diminished by GS and LL extracts. After 4 weeks of feeding on a high cholesterol diet (HCD), zebrafish exhibited serum total cholesterol (TC) and triglyceride (TG) levels 2.5 -fold higher than those fed a normal diet (ND). Within the experimental group, those fed acai demonstrated the lowest serum TC and CETP activity, while the LL-consuming group showed a reduction in serum TC and TG relative to HCD-fed fish. Serum glucose levels also increased in the HCD group, to threefold above the ND group; GS and LL feeding elicited the greatest reduction in hyperglycemia. The groups consuming acai and LL showed much less hepatic inflammation, as well as attenuation of fatty liver and a reduced content of oxidized species. In conclusion, extracts
\end{abstract}

Correspondence to: Professor Kyung-Hyun Cho, School of Biotechnology, Yeungnam University, Gyeongsan 712-749, Republic of Korea

E-mail: chok@yu.ac.kr

${ }^{*}$ Contributed equally

Key words: antioxidant, atherosclerosis, diabetes, zebrafish, citrus, grape of LL, GS, and acai shared antioxidant, anti-inflammatory and anti-atherosclerotic activity in cellular assays and in a hypercholesterolemic zebrafish model.

\section{Introduction}

Flavonoids and phenolics are well established as containing potent antioxidants. A search for antioxidants from common plants is ongoing to reduce the risk of severe conditions such as cancer, cardiovascular and immune diseases, and metabolic syndrome, which are all complications of diabetes and obesity (1). From among the major fruit and vegetable sources of antioxidants, in the current study we selected loquat, acai, and grape for a comparison of anti-atherosclerotic and antidiabetic activities after a survey of the literature.

Loquat leaves (LL) and certain kinds of berries, such as grapes, are known to be enriched in polyphenol and flavonoid compounds. The leaves of the loquat, Eriobotrya japonica, have been widely used as a traditional medicine to treat a variety of diseases including asthma, gastroenteric disorders, diabetes, and cancer (2). In particular, LL terpenoids induce hypoglycemia in diabetic mice (3), and a hydrophilic extract of the loquat has shown antitumor activity (4). In addition to the leaf, the loquat flower and seed also possess antioxidant capacity (5), in addition to anti-senescence activities in rat fibroblasts (6).

The acai berry, fruit of the acai palm (Euterpe oleracea Mart.), has garnered interest as a health-food additive due to its substantial antioxidant content (7) and anti-atherosclerotic activity (8). Acai pulp and juice exhibited antioxidant potential and attenuated atherosclerosis in apo-E deficient mice (9). Additionally, acai extracts containing glycosides and aglycones showed antitumor activity in leukemia cells (9). Polysaccharides isolated from acai fruit induce innate immune responses to treat asthma and infectious disease (10), although interestingly a toxicity study revealed absence of genotoxicity from acai pulp consumption (11).

Grapes and grape byproducts are equally well known for their antioxidant effects; grape skin (GS) extract has been reported to exert a potent hypoglycemic effect and 
counter inflammation in a mouse model for obesity (12). GS exhibits several bioactive properties for the treatment of obesity-related hyperglycemia (13) and hyperlipidemia (14), along with inhibition of protein glycation (15). Grape and its byproducts are well-known natural sources of beneficial bioactive compounds such as anti-oxidants and anti-aging agents, including resveratrol (16). The latter, found in red grapes, has reported preventive and therapeutic effects against such diseases as cancer (17), cardiovascular disease (16), and skin disorders (18). Since resveratrol is mainly found in GS, it has been proposed that GS has wide industrial applicability in the development of healthy and functional foods.

No reports have yet evaluated the in vitro or in vivo antiatherosclerotic and anti-diabetic capacity of aqueous-phase extracts of these three sources of antioxidants. We used a zebrafish (Danio rerio) model of hypercholesterolemia induced by a high cholesterol (HC) diet to investigate the physiological effects of antioxidant water extracts on vertebrates. Our model, mimics early hyperlipidemia and its complications, as suggested by the Stoletov et al (19) and our own research group (20). By feeding adult zebrafish an HC diet for several weeks, we induced atherosclerosis concomitant with hypercholesterolemia, lipoprotein oxidation, and fatty streak formation with elevated levels of the pro-inflammatory response.

In the current report, water extracts of acai, LL and GS were used to compare antioxidant inhibitory activities against glycation of apoA-I and anti-atherosclerotic activity in vitro and in vivo in hypercholesterolemic zebrafish.

\section{Materials and methods}

Materials. LL were purchased from a local herbal market (Daegu, South Korea) and extracted with hot water by heating for $2 \mathrm{~h}$ at $70^{\circ} \mathrm{C}$. The extract was then lyophilized and re-dissolved in water to $0.1 \mathrm{mg} / \mathrm{ml}$.

GS (1 kg, moisture content, 93\%) was provided by Foodwell Co., Ltd. (Daegu, South Korea), and was extracted with hot water for $2 \mathrm{~h}$, then concentrated using a rotary evaporator (N-1000; Tokyo Rikakikai Co., Ltd., Tokyo, Japan).

Acai (Euterpe oleracea Mart.) puree was obtained from All-In-One International Company (Seoul, South Korea). Acai puree (moisture content $86.5 \%$ ) was lyophilized, extracted in hot water at $70^{\circ} \mathrm{C}$, and centrifuged $(2,000 \mathrm{x}$ g) to separate solids

Total phenolic content of the extracts was determined by using phosphomolybdic-phosphotungstic acid including FolinCiocalteu reagent (22). Briefly, each sample $(0.1 \mathrm{mg} / \mathrm{ml}, 50 \mathrm{ml})$ was filtered with Whatman \#1 paper and an aliquot $(0.5 \mathrm{ml})$ of the sample added to $2.5 \mathrm{ml}$ of $0.2 \mathrm{~N}$ Folin-Ciocalteu reagent for a 5-min incubation. $\mathrm{Na}_{2} \mathrm{CO}_{3}$ of $2 \mathrm{ml} 75 \mathrm{~g} / 1$ were then added and the total volume was raised to $25 \mathrm{ml}$ with distilled water; this solution was incubated at room temperature for $2 \mathrm{~h}$. Absorbance was measured at $760 \mathrm{~nm}$ using a 1-cm cuvette in a Perkin-Elmer UV-Vis Lambda 25 spectrophotometer. Tannic acid (0-800 mg/l) was used to produce a standard calibration curve. Total phenolic content was expressed in mg of tannic acid equivalents (TAE per gram of extract.

Total flavonoid content was determined by the Dowd method as modified by Meda et al (23). Five milliliters of $2 \%$ aluminum trichloride $\left(\mathrm{AlCl}_{3}\right)$ in methanol were mixed with the same volume of extract $(0.4 \mathrm{mg} / \mathrm{ml})$. Absorption readings were obtained at $415 \mathrm{~nm}$ after 10 min using a UV-Vis spectrophotometer (Ultrospec 2100 Pro; Amersham Biosciences, Amersham, UK) against a blank sample consisting of $5 \mathrm{ml}$ extract solution with $5 \mathrm{ml}$ methanol without $\mathrm{AlCl}_{3}$. Total flavonoid content was determined using a standard curve of catechin dilutions (0-100 mg/l). Total flavonoid content was expressed as mg of catechin equivalents per gram of extract.

Total anthocyanin content was determined spectrophotometrically by the $\mathrm{pH}$ differential method (24) and calculated using $\mathrm{mg} / \mathrm{l}$ equivalents of cyanidin-3-glucoside with an extinction coefficient of 29,600 (25).

Ferric reducing ability assay. Ferric reducing ability (FRA) was determined using a previously described method (26) with slight modifications (27). Briefly, freshly prepared FRA reagent $(300 \mu \mathrm{l})$ was mixed with each extract or tissue homogenate as an antioxidant source, after which FRA was determined by measuring the absorbance at $593 \mathrm{~nm}$ every $20 \mathrm{sec}$ over a 10 -min period at $25^{\circ} \mathrm{C}$ using a DU800 spectrophotometer (Beckman Coulter, Fullerton, CA, USA) equipped with a MultiTemp III thermocirculator (Amersham, Uppsala, Sweden).

Extract inhibitory activity against copper-mediated LDL oxidation. Fresh human low-density lipoprotein (LDL; $300 \mu \mathrm{g}$ of protein) was incubated with each extract (final concentration, $1 \mu \mathrm{g} / \mathrm{ml})$ in a $500-\mu 1$ reaction volume in the presence of $10 \mu \mathrm{M}$ (final concentration) $\mathrm{CuSO}_{4}$ for up to $2 \mathrm{~h}$. During incubation, conjugated diene formation was monitored at $234 \mathrm{~nm}$ at $24.5^{\circ} \mathrm{C}$ (28) using a DU800 spectrophotometer equipped with a MultiTemp III thermocirculator. In order to verify spectroscopic data, oxidized LDL samples were subjected to electrophoresis on a $0.5 \%$ agarose gel for comparison of relative electromobility (29).

Purification of apoA-I and non-enzymatic glycation. Human plasma was obtained from healthy male volunteers at the Yeungnam University Hospital (Daegu, South Korea). ApoA-I was purified from the human plasma high-density lipoprotein (HDL) fraction $(1.063<\mathrm{d}<1.225)$ using ultracentrifugation and column chromatography following the method described by Brewer et al (30). Purified apoA-I was lyophilized and stored at $-80^{\circ} \mathrm{C}$ until use.

Determination of apoA-I glycation was carried out according to the method of McPherson et al (31) with slight modifications, including the use of human apoA-I $(20,21)$. The extent of glycation was determined by reading the fluorometric intensity at $370 \mathrm{~nm}$ (excitation, Ex) and $440 \mathrm{~nm}$ (emission, Em) using a spectrofluorometer (LS55; Perkin-Elmer, Norwalk, CT, USA) with WinLab software package 4.00 (Perkin-Elmer). Each extract (final concentration, $10 \mu \mathrm{g} / \mathrm{ml} ; 10 \mu \mathrm{l}$ volume) was treated to test its inhibitory ability in a $100-\mu 1$ reaction volume. Percentage inhibition was calculated from fluorescence intensity (FI) with the following formula:

$\%$ inhibition $=100 \times\left\{1-\left[\frac{\text { sample FI }- \text { background FI }}{\text { negative control FI - background FI }}\right]\right\}$

where sample FI = apoA-I $(0.1 \mathrm{mg} / \mathrm{ml} ; 82 \mu \mathrm{l})+$ fructose (final concentration, $250 \mathrm{mM} ; 8 \mu \mathrm{l})+$ each water extract (final concentration, 10 or $100 \mu \mathrm{g} / \mathrm{ml} ; 10 \mu \mathrm{l})$; background $\mathrm{FI}=$ apoA-I; and negative control FI = apoA-I + fructose + water. 
In order to confirm spectrofluorometry data, glycated apoA-I was electrophoresed on 15\% SDS-PAGE gels with or without extract; more-extensively glycated apoA-I showed a tendency to multimerize, as previously reported $(32,33)$.

Cholesteryl ester transfer assays. Recombinant HDL (rHDL) was synthesized in accordance with the method described by Cho (34) with trace amounts of $\left[{ }^{3} \mathrm{H}\right]$-cholesteryl oleate (TRK886, $3.5 \mu \mathrm{Ci} / \mathrm{mg}$ of apoA-I; GE Healthcare, Uppsala, Sweden) to act as a CE donor containing apoA-I and cholesteryl oleate. Human serum $(0.05 \mathrm{ml})$ and LDL $(0.25 \mathrm{mg} / \mathrm{ml}$, $0.05 \mathrm{ml}$ volume) were used as CETP and CE-acceptor sources, respectively. Different concentrations of each extract (in $0.01 \mathrm{ml}$ volume) were added as CETP inhibitors.

CETP inhibition was calculated as follows:

$\%$ inhibition $=100 \times\left\{1-\left[\frac{\text { sample }(\mathrm{cpm})-\text { blank }(\mathrm{cpm})}{\text { control }(\mathrm{cpm}) \text { - blank }(\mathrm{cpm})}\right]\right\}$

where sample is extract treated as a source of inhibitor and the control lacks inhibitor.

Purification of LDL, oxidation, and acetylation. LDL $(1.019<\mathrm{d}<1.063)$ was purified from healthy human plasma obtained from the blood bank of Yeungnam University Medical Center (Daegu, South Korea) by ultracentrifugation according to standard protocols (35). The density was appropriately adjusted by the addition of $\mathrm{NaCl}$ and samples were centrifuged for $22 \mathrm{~h}$ at $10^{\circ} \mathrm{C}$ and $100,000 \mathrm{x}$ g using a Himac CP-90 $\alpha$ (Hitachi, Tokyo, Japan) at the Instrumental Analysis Center of Yeungnam University. Oxidized LDL (oxLDL) was produced by incubating the LDL $(1.019<\mathrm{d}<1.063)$ fraction with $\mathrm{CuSO}_{4}$ (final concentration, $10 \mu \mathrm{M}$ ) for $4 \mathrm{~h}$ at $37^{\circ} \mathrm{C}$. OxLDL was then filtered $(0.2 \mu \mathrm{m})$ and analyzed using the thiobarbituric acid reacting substances (TBARS) assay to determine the extent of oxidation, as described previously (36).

LDL acetylation (to generate acLDL) was performed using saturated sodium acetate and acetic anhydride, according to a previously described method (37). After acetylation and subsequent dialysis, the acLDL protein content was determined and samples were filtered prior to use.

Assays for anti-atherosclerotic activity. THP-1 cells, a human monocyte cell line, were obtained from the American Type Culture Collection (ATCC) (\#TIB-202; Manassas, VA, USA) and maintained in RPMI-1640 medium (Hyclone, Logan, UT, USA) supplemented with $10 \%$ fetal bovine serum (FBS), until needed for experimentation. Cells that had undergone no more than 20 passages were incubated in medium containing phorbol 12-myristate 13-acetate (PMA; final concentration, $150 \mathrm{nM}$ ) in 24-well plates for $48 \mathrm{~h}$ at $37^{\circ} \mathrm{C}$ in a humidified incubator $\left(5 \% \mathrm{CO}_{2}\right.$ and $95 \%$ air) to induce differentiation as macrophages.

To compare anti-atherosclerotic activity using a cellular model, each extract $(0.1 \mathrm{mg} / \mathrm{ml})$ was assayed for its effect on macrophage oxLDL uptake, as previously reported by our research group (34). Differentiated and adherent macrophages were then rinsed with warm PBS and incubated with $400 \mu \mathrm{l}$ of fresh RPMI-1640 medium containing 1\% FBS, $50 \mu \mathrm{l}$ of oxLDL (50 $\mu \mathrm{g}$ of protein in PBS) or acLDL (50 $\mu \mathrm{g}$ of protein in PBS), and $50 \mu \mathrm{l}$ of each extract, for $48 \mathrm{~h}$ at $37^{\circ} \mathrm{C}$ in a humidi- fied incubator. After incubation, the cells were stained with Oil Red O solution (0.67\%) to visualize the amount of lipid species in the cell.

In vivo assays with hypercholesterolemic zebrafish. Zebrafish maintenance and experimental procedures were approved by the Committee of Animal Care and Use of Yeungnam University (Gyeongsan, South Korea). A high cholesterol (HC) diet containing $4 \%$ cholesterol was made by soaking tetrabit [Tetrabit Gmbh D49304; $47.5 \%$ crude protein, $6.5 \%$ crude fat, $2.0 \%$ crude fiber, $10.5 \%$ crude ash, containing vitamin A $(29,770 \mathrm{IU} / \mathrm{kg})$, vitamin D3 (1,860 IU $/ \mathrm{kg})$, vitamin E $(200 \mathrm{mg} / \mathrm{kg})$, and vitamin C $(137 \mathrm{mg} / \mathrm{kg})$; (Melle, Germany)] in a solution of cholesterol (Sigma \#C-3045; Sigma-Aldrich, St. Louis, MO, USA) in diethyl ether. After ether evaporation, $\mathrm{HC}$ diet was mixed with lyophilized fruit extract (a final concentration of 10\% w/w of powder/tetrabit). Each group ( $\mathrm{n}=70)$ consumed the designated diet $(20 \mathrm{mg} / \mathrm{day} / \mathrm{fish})$, as shown in Table II. The zebrafish were maintained at $28 \pm 1^{\circ} \mathrm{C}$ under a $14 \mathrm{~h}: 10 \mathrm{~h}$ light:dark cycle.

After feeding for 5 weeks, blood $(2 \mu \mathrm{l})$ was drawn from the heart of adult fish and combined with $5 \mu 1$ of PBS-EDTA, then collected into EDTA-treated tubes (final concentration, $1 \mathrm{mM}$ ). Serum total cholesterol (TC), HDL-cholesterol, and triglycerides (TG) were determined using a commercial assay kit (cholesterol, T-CHO; triglycerides, Cleantech TS-S; were from Wako Pure Chemical, Osaka, Japan). CETP activity of zebrafish serum samples was compared among groups.

Hepatic tissue analysis. Hepatic tissues were collected from the same lobes of at least 15 zebrafish, flash-frozen in liquid nitrogen, and stored at $-70^{\circ} \mathrm{C}$. Frozen liver sections were sliced to a thickness of $7 \mu \mathrm{m}$ using a microtome (CM1510S; Leica, Nussloch, Germany), and stained with Oil Red O and hematoxylin in order to evaluate any light-microscopic features or fatty liver changes. Morphological changes were compared with a Nikon Eclipse TE2000 microscope (Tokyo, Japan).

An aliquot of hepatic tissue (50 $\mathrm{mg}$ of liver in $0.5 \mathrm{ml}$ of PBS) from each group was homogenized for $3 \min (150 \mathrm{x} \mathrm{g})$ in an ice bath using a tissue homogenizer (Euro-ST; Eurostar, IKA-Werke, Staufen, Germany). After brief centrifugation $(10,000 \times \mathrm{g}, 3 \mathrm{~min})$, protein concentration in the supernatants was determined and supernatants were resuspended at an equal concentration.

Malondialdehyde (MDA) levels in each homogenate were determined by adding $10 \mathrm{mM}$ 1-methyl-2-phenylindole to each sample for color development, as described previously (38). Reactions were initiated by adding $\mathrm{HCl}$ (final concentration, $5 \%$ ) and incubated for $1 \mathrm{~h}$ at $45^{\circ} \mathrm{C}$. After the reaction, mixtures were centrifuged and absorbance readings of supernatants were taken at $586 \mathrm{~nm}$. The MDA content was calculated from a calibration curve using an MDA standard (1,1,3,3-tetramethoxy propane, Sigma \#T9889; Sigma-Aldrich).

Statistical analysis. All data are expressed as the mean \pm SD from at least three independent experiments with duplicate samples. Comparisons between results were made by analysis of variance (ANOVA) and differences were assessed by the Student's t-test using the SPSS program (version 14.0; SPSS, Inc., Chicago, IL, USA) for in vitro experiments. In Table II, for 
Table I. Total amount of phenolics and flavonoid compounds of the plant extracts.

\begin{tabular}{lcccc}
\hline Phytochemical compound (mg/g plant extract) & Yields $(\%)$ & Total phenols & Total flavonoid & Anthocyanin content (mg/l) \\
\hline Loquat leaf (LL) (Eriobotrya japonica) & 8.9 & $30.23 \pm 0.25$ & $11.28 \pm 0.52$ & ND \\
Grape skin (GS) & 4.5 & $74.85 \pm 0.50$ & $32.26 \pm 1.46$ & $235.65 \pm 5.7$ \\
Acai & $9.8^{\mathrm{a}}$ & $40.37 \pm 1.15$ & $2.02 \pm 1.01$ & $251.43 \pm 3.5$ \\
\hline
\end{tabular}

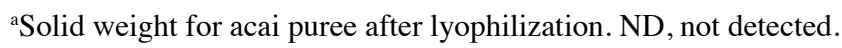

A

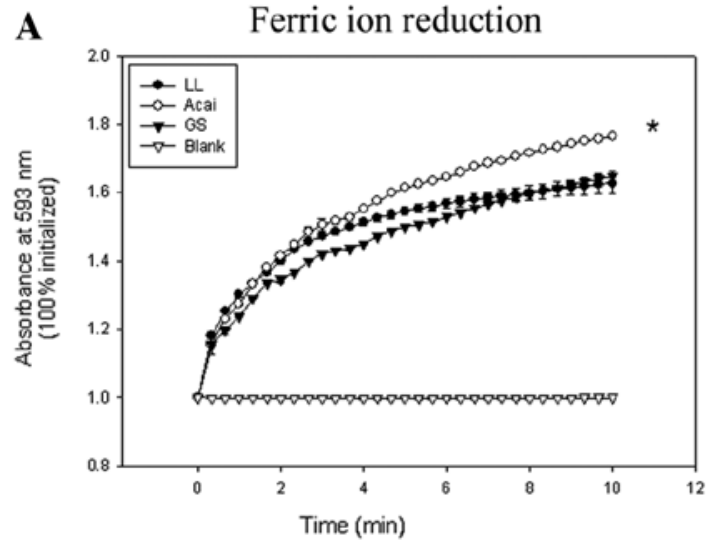

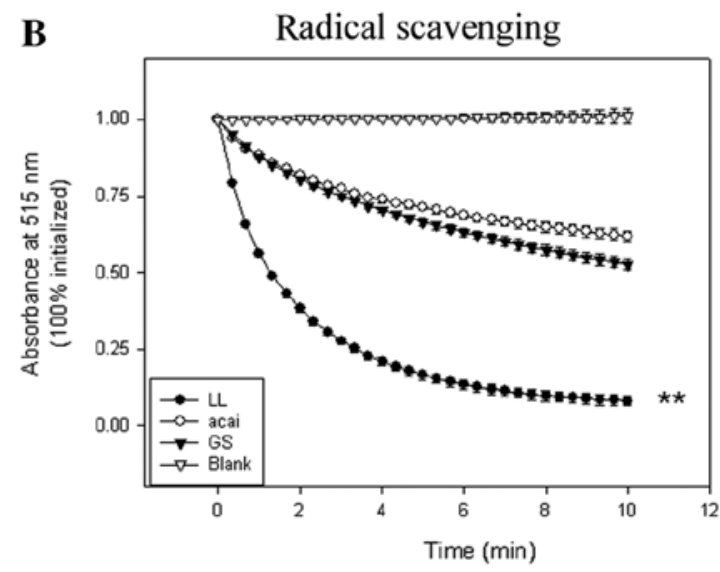

Figure 1. Antioxidant activity of water-extracted fruit (final concentration, $0.1 \mathrm{mg} / \mathrm{ml}$ ). (A) Comparison of a reductive potential as assessed by ferric ion reduction ability. ${ }^{*} \mathrm{P}<0.05$ vs. LL after 10 -min incubation. (B) Radical-scavenging activity determined against 2 -diphenyl-1-picrylhydrazyl (DPPH). ${ }^{* *} \mathrm{P}<0.01 \mathrm{vs}$. acai.

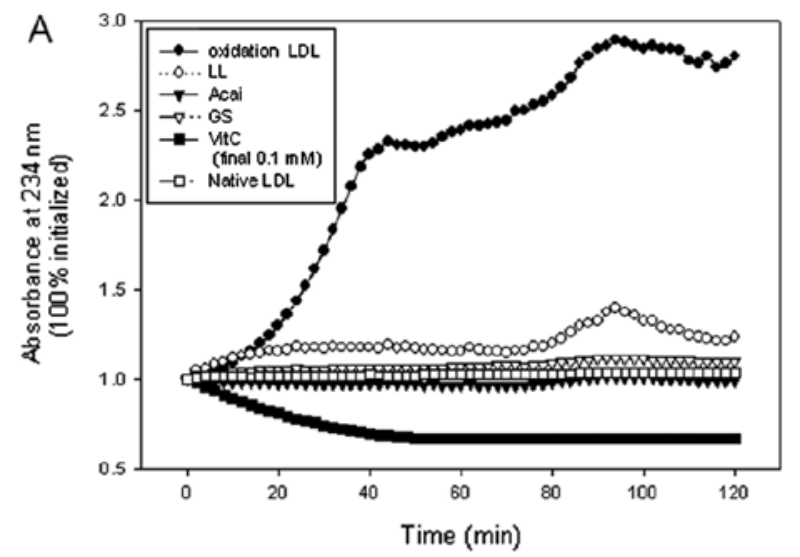

B

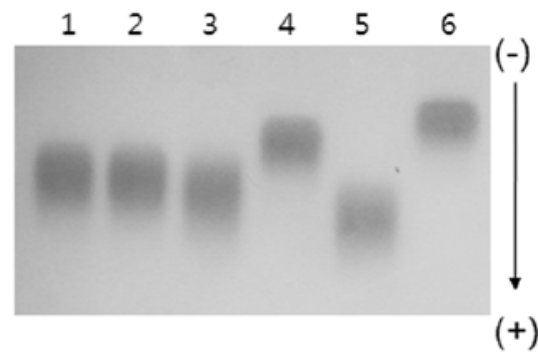

Figure 2. Water-extract inhibitory ability in cupric ion-mediated LDL oxidation. (A) Continuous monitoring of conjugated diene levels by absorbance at $234 \mathrm{~nm}$ wavelength $\left(\mathrm{A}_{234}\right)$ during $\mathrm{Cu}^{2+}$-mediated LDL oxidation in the presence of each extract (final concentration, $0.1 \mathrm{mg} / \mathrm{ml}$ ). (B) Relative electrophoretic mobility profiles of LDL samples from copper-mediated oxidation (final $10 \mu \mathrm{M}$ of $\left.\mathrm{Cu}^{2+}\right)$. More-oxidized LDL migrates faster toward the cathode $(0.5 \%$ agarose). $1, \mathrm{LL}+\mathrm{LDL}+\mathrm{Cu}^{2+} ; 2$, acai $+\mathrm{LDL}+\mathrm{Cu}^{2+} ; 3, \mathrm{GS}+\mathrm{LDL}+\mathrm{Cu}^{2+} ; 4$, Vit $\mathrm{C}($ final $500 \mu \mathrm{M})+\mathrm{LDL}+\mathrm{Cu}{ }^{2+} ; 5, \mathrm{LDL}+\mathrm{Cu}{ }^{2+} ; 6$, native $\mathrm{LDL}$ alone.

in vivo tests, data were evaluated via one-way ANOVA using SPSS and the differences between the means were assessed using the Duncan's multiple-range test. Statistical significance was defined as $\mathrm{P}<0.05$.

\section{Results and Discussion}

Phenolics, flavonoids, and anthocyanins in extracts. We performed hot-water extractions on fruit samples to isolate antioxidant compounds. As shown in Table I, phenolics and flavonoids were enriched in GS extract, which contained
2.5- and 1.9-fold more total phenols than LL and acai, respectively. In the same quantity of extract, LL possessed 5.5-fold higher flavonoid content than acai; however, the acai extract exhibited 1.3-fold more phenol content than the LL fraction. Anthocyanin content was similar in GS and acai extracts although they were not identified in LL.

In vitro antioxidant activity. As shown in Fig. 1A, acai, LL, and GS extract demonstrated the strongest ferric ion reductive ability (FRA), with 77, 65 and 63\% increases from initial levels, respectively. However, the GS extract showed the highest 
A

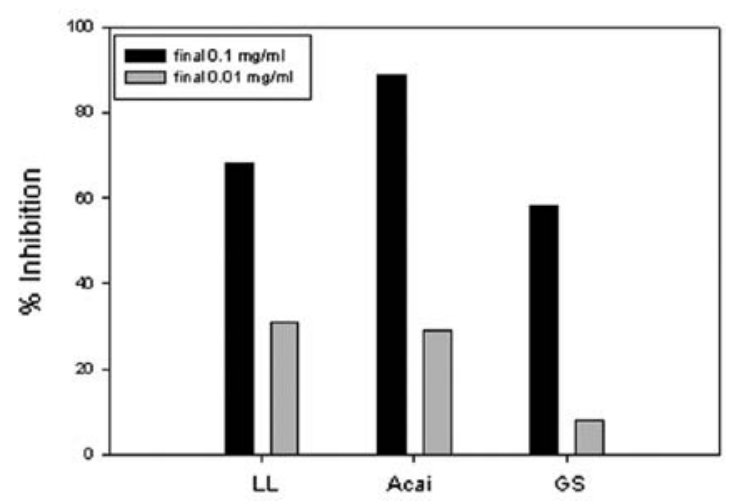

B

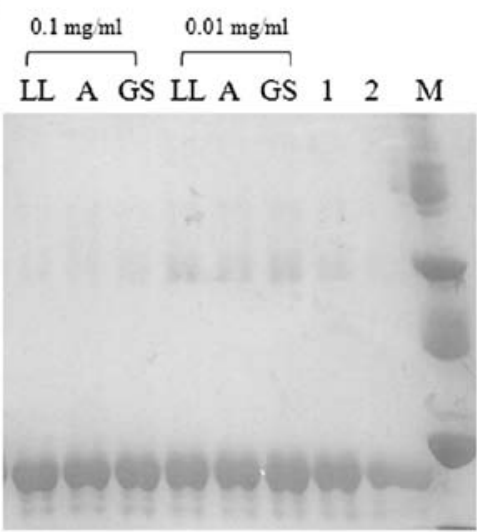

Figure 3. Water-extract inhibition of glycation (final concentration, 10 or $100 \mu \mathrm{g} / \mathrm{ml}$ ). (A) Anti-glycation activity determined by spectrofluorometry (Ex=370 nm, $\mathrm{Em}=440 \mathrm{~nm}$ ). Percent inhibition of glycation is calculated as described in Materials and methods. (B) Electrophoretic mobility of native and glycated apoA-I (12\% SDS-PAGE gels). Glycated apoA-I (lane 1) exhibits more multimerized bands than the control (lane 2, apoA-I alone). LL, loquat leaves; A, acai; GS, grape skin.
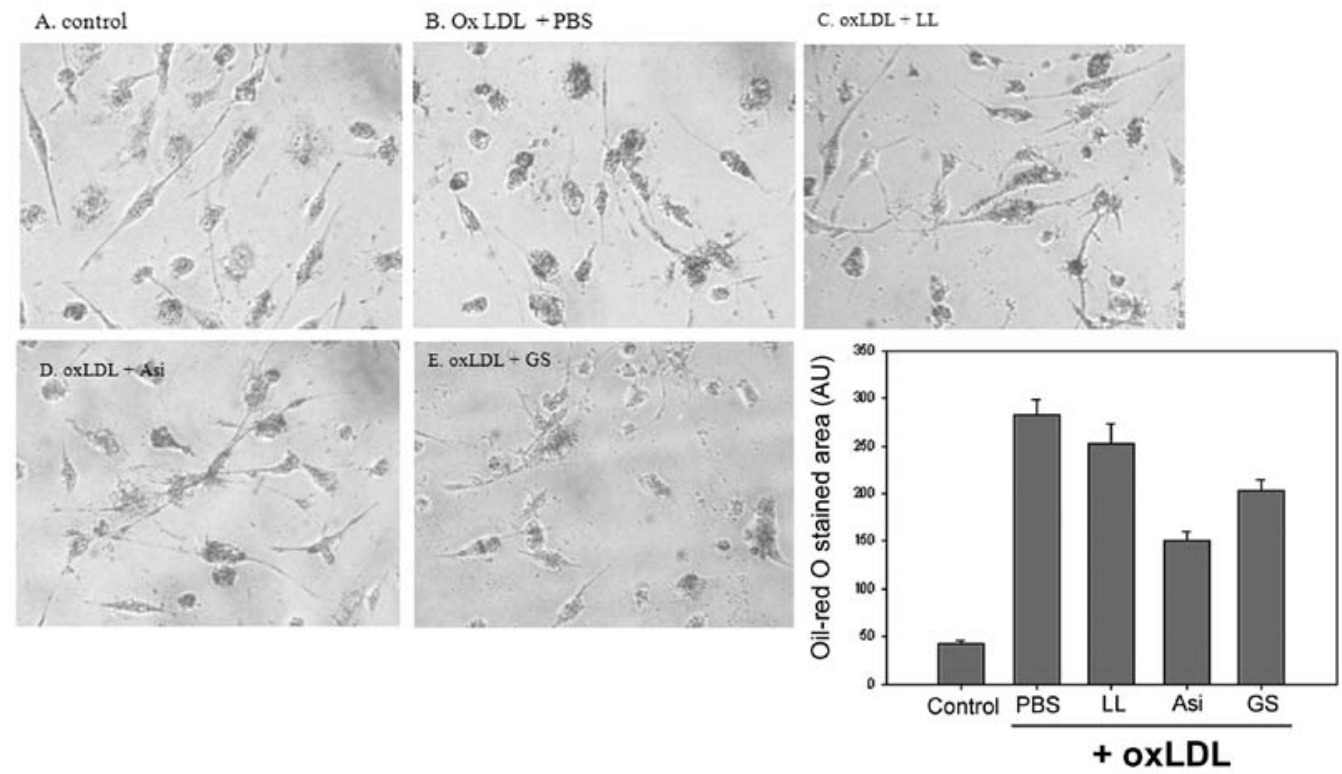

Figure 4. Macrophage uptake of oxLDL in the presence of antioxidant extracts (final concentration, $0.1 \mathrm{mg} / \mathrm{ml}$ ). The extent of macrophage uptake of lipids or LDL in the presence of antioxidant extracts was compared by Oil Red O staining.

initial absorbance at $593 \mathrm{~nm}$ (data not shown), indicating that its FRA was most pronounced.

In a DPPH radical-scavenging assay (Fig. 1B), the LL fraction showed the strongest scavenging activity, removing approximately $92 \%$ of radicals. LL and acai fractions showed 47 and $38 \%$ radical removal, respectively, during the same length of incubation (Fig. 1B).

Cupric-ion mediated LDL oxidation was inhibited by all extracts (Fig. 2A). LDL exposed to each extract treated showed no increase in A234 except in samples treated with LL; these demonstrated an absorbance increase of approximately 23\% (Fig. 2A). Agarose gel electrophoresis confirmed that electromobility of extract-treated LDL was reduced relative to oxidized LDL, which demonstrated a smear with faster migration due to apo-B fragmentation and increased negative charge. As a positive control, vitamin $\mathrm{C}$ treated LDL (final concentration, $0.5 \mathrm{mM}$ ) showed no increase of $\mathrm{A}_{234}$ and the slowest electromobility.
Anti-glycation activity. As shown in Fig. 3, acai extract exhibited the strongest anti-glycation activity of those assayed, at $89 \%$ relative to the control at a final concentration of $0.1 \mathrm{mg} /$ $\mathrm{ml}$, although LL and GS extracts could also reduce glycation concentration-dependently (68 and 58\% inhibition, respectively). Electrophoresis on $15 \%$ SDS-PAGE gels identified a higher degree of multimerization in glycated apoA-I samples (lane 7) relative to control apoA-I (Fig. 3B; lane 8). However, apoA-I exposed to high dosage of extracts (final concentration, $0.1 \mathrm{mg}$ / ml) showed almost no multimerization (Fig. 3B; lanes 1-3).

Inhibition of modified LDL uptake into macrophages. Oxidized LDL was phagocytosed strongly by macrophages compared with native LDL (Fig. 4A). Among the extracts, treatment with acai evoked the highest LDL uptake (Fig. 4D), leading to an approximately $47 \%$ reduction in Oil Red O staining relative to PBS treatment in the presence of oxLDL. However, treatment with the LL (Fig. 4C) and GS (Fig. 4E) fractions elicited weaker 

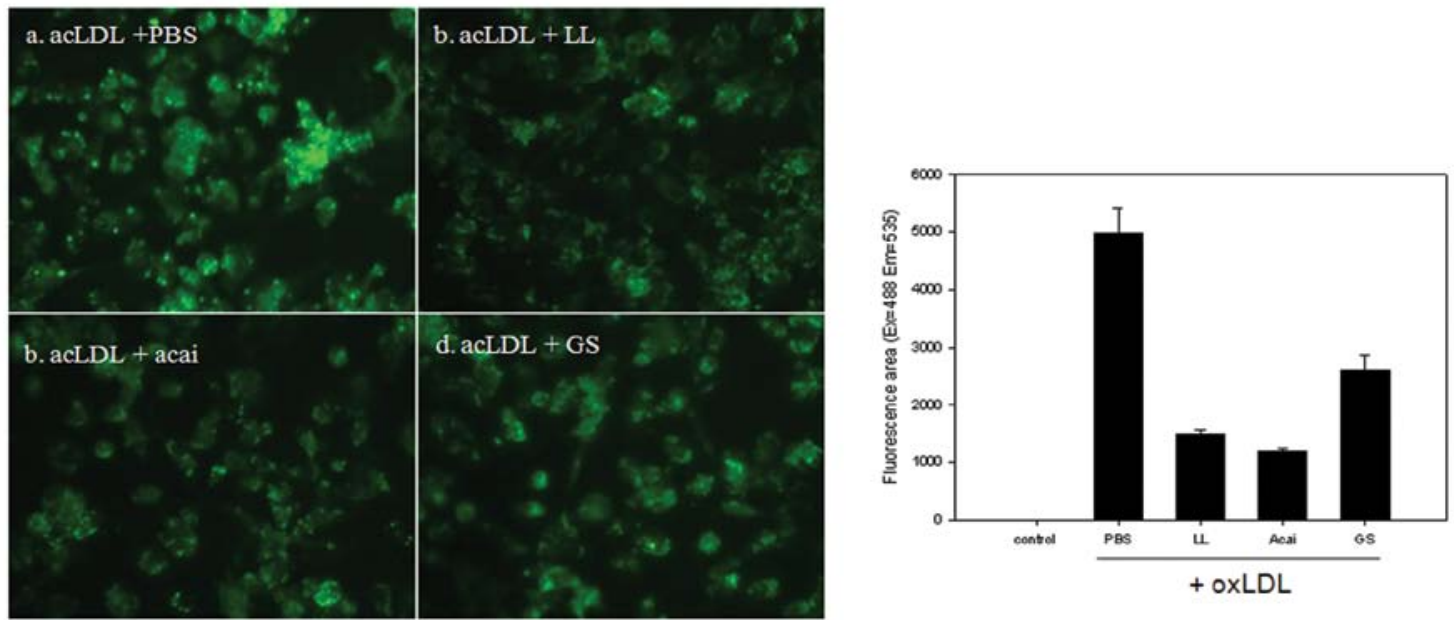

Figure 5. Inhibition of macrophage acLDL phagocytosis. Differentiated THP-1 cells were incubated with each antioxidant extract (final concentration, $0.1 \mathrm{mg} / \mathrm{ml}$ ) for $48 \mathrm{~h}$ with or without $50 \mu \mathrm{l}$ of acLDL ( $50 \mu \mathrm{g}$ protein). The extent of acLDL uptake was visualized by fluorescence microscopy.

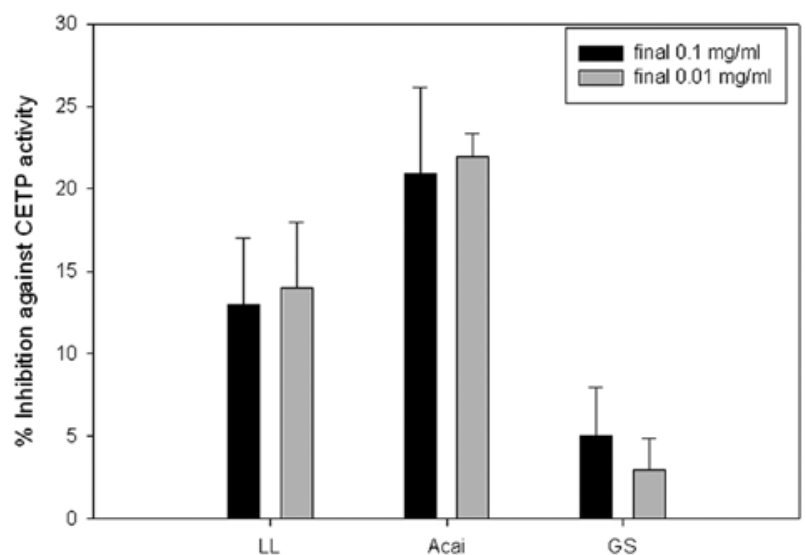

Figure 6. Antioxidant-extract inhibition of CETP activity. Equal volumes of human plasma $(0.02 \mathrm{ml})$ and extract were utilized as a source of CETP or CETP inhibitor, respectively. Human LDL $(0.25 \mathrm{mg} / \mathrm{ml}$ of protein) and rHDL ( $0.05 \mathrm{mg}$ of protein) containing $\left[{ }^{3} \mathrm{H}\right]$-cholesteryl oleate were used as $\mathrm{CE}$ acceptor and CE donor, respectively. Error bars indicate the SD from three independent experiments with duplicate samples.

inhibitory activity, with approximately $11 \%$ and $29 \%$ less staining than PBS treatment, respectively.

Uptake of acLDL was also inhibited by treatment with all extracts (Fig. 5). In particular, treatment with acai, LL, and GS extracts caused 76, 70 and $48 \%$ inhibition, respectively, of uptake in the presence of acLDL compared with PBS treatment. In cell-based assays, acai extract showed the strongest inhibition of uptake of LDL modified by either oxidation or acetylation.

CETP inhibition. As shown in Fig. 6, all fractions showed moderate in vitro CETP inhibitory activity of 5-22\% with treatment of either 0.1 or $0.01 \mathrm{mg} / \mathrm{ml}$ extract (final concentration). Acai manifested the most pronounced CETP inhibitory capacity at $0.01 \mathrm{mg} / \mathrm{ml}$, but no increase was detected with higher concentration $(0.1 \mathrm{mg} / \mathrm{ml})$. However, the GS extract did not show notable inhibition activity against human CETP.

Currently, many pharmaceutical companies are developing CETP inhibitors, as CETP is established to be atherogenic (39).
CETP promotes the redistribution and equilibration of $\mathrm{CE}$ and TG between HDL and apo-B harboring proteins (LDL). It has been proposed that inhibition of CETP might augment levels of HDL-C (40).

Hypolipidemic and hypoglycemic activity in zebrafish. After 4 weeks feeding on an HCD, serum TC and TG levels of group 2 (HCD group) were increased around 2.5-fold above levels in group 1 (control) (Table II). Zebrafish groups fed LL (group 3 ) or acai (group 4) showed 5 and $9 \%$ decreases in serum TC, respectively, while the grove consuming GS showed an $8 \%$ increase in serum TC compared with the HC control (group 2). LL- and GS-consuming groups showed 20 and $6 \%$ decreases, respectively, in serum TG compared with HC control. However, the acai-consuming group demonstrated a $14 \%$ increase in serum TG.

Serum glucose levels were 3 -fold increased in group 2 compared with controls (group 1), indicating that increased cholesterol uptake might be connected to an increase in plasma blood glucose to elevate serum glucose levels, in good agreement with our previous report (20). LL- and GS-consuming groups demonstrated remarkable hypoglycemia, with blood glucose reduced below that of the ND control (group 1). Although the acai-fed group (group 4) showed lower serum glucose than the HCD group (group 2), its capacity to reduce blood glucose was weakest among extracts.

Interestingly, the acai palm's primary fatty acid is monounsaturated oleic acid (7). Monoacylglycerol (MAG) containing oleic acid has been reported to exert potent antioxidant effects (41), suggesting that oleic acid might impart some degree of acai's antioxidant efficacy.

In vivo CETP activity. CETP activity was nearly 1.4-fold higher in the serum of hypercholesterolemic zebrafish (group 2) than the normolipidemic (group 1; $0.02 \mathrm{ml}$ serum tested for each group), indicating that HCD consumption elevates CETP activity as well as blood cholesterol. Among the groups fed HCD, those treated with acai exhibited the lowest CETP activity (33\% lower than group 2), while the GS-fed group (group 5) showed slightly higher serum CETP activity than 
Table II. Blood profiles of hypercholesterolemic zebrafish after 4 weeks of feeding.

\begin{tabular}{|c|c|c|c|c|c|}
\hline & $\begin{array}{l}\text { Group } 1 \\
\text { Normal diet } \\
\text { (ND) }\end{array}$ & $\begin{array}{c}\text { Group } 2 \\
\text { HC (high } \\
\text { cholesterol diet) }\end{array}$ & $\begin{array}{c}\text { Group } 3 \\
\text { HC + LL } \\
(10 \% \text { w/w powder })\end{array}$ & $\begin{array}{c}\text { Group } 4 \\
\text { HC + Asi } \\
(10 \% \text { w/w powder })\end{array}$ & $\begin{array}{c}\text { Group } 5 \\
\text { HC + GS } \\
(10 \% \mathrm{w} / \mathrm{w} \text { powder })\end{array}$ \\
\hline $\mathrm{TC}(\mathrm{mg} / \mathrm{dl})$ & $275 \pm 4.5^{\mathrm{a}}$ & $677 \pm 16^{\mathrm{b}}$ & $645 \pm 75^{b}$ & $619 \pm 12^{c}$ & $733 \pm 24^{b}$ \\
\hline TG (mg/dl) & $142 \pm 15^{\mathrm{a}}$ & $349 \pm 42^{b}$ & $279 \pm 10^{c}$ & $398 \pm 42^{\mathrm{b}}$ & $329 \pm 17^{b}$ \\
\hline Glucose (mg/dl) & $55 \pm 5^{\mathrm{a}}$ & $164 \pm 21^{\mathrm{b}}$ & $48 \pm 7^{\mathrm{a}}$ & $108 \pm 16^{c}$ & $41 \pm 2^{\mathrm{a}}$ \\
\hline $\begin{array}{l}\text { CETP activity } \\
\text { (\% CE-transfer) }\end{array}$ & $15 \pm 2^{\mathrm{a}}$ & $21 \pm 1^{b}$ & $20 \pm 1^{b}$ & $14 \pm 1^{\mathrm{a}}$ & $28 \pm 2^{c}$ \\
\hline
\end{tabular}

${ }^{1}$ Tetrabit ${ }^{\oplus:}$ : Tetrabit $[47.5 \%$ crude protein, $6.5 \%$ crude fat, $2.0 \%$ crude fiber, $10.5 \%$ crude ash, containing vitamin A (29,770 IU/kg), vitamin D3 $(1,860 \mathrm{IU} / \mathrm{kg})$, vitamin E $(200 \mathrm{mg} / \mathrm{kg})$, and vitamin C $(137 \mathrm{mg} / \mathrm{kg})] .{ }^{\mathrm{a}-\mathrm{d}}$ The mean values not sharing a common letter in the same row are significantly different between groups $(\mathrm{P}<0.05)$. CETP, cholesteryl ester transfer protein; GS, grape skin; LL, loquat leaves; HC, high cholesterol; TC, total cholesterol; TG, triacylglycerol.
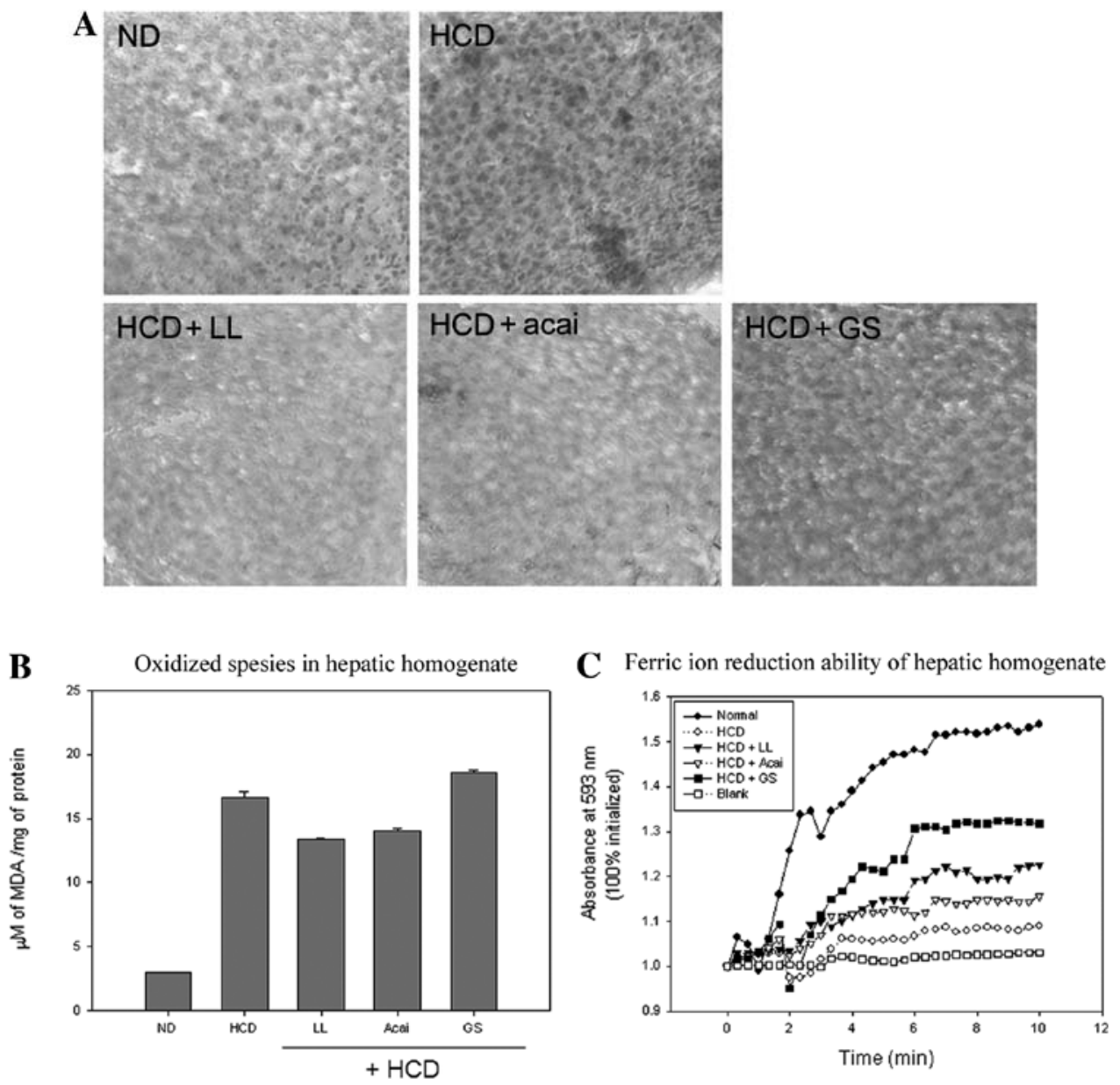

Figure 7. Histological assessment of hepatic tissue comparing anti-inflammatory and antioxidant activity in zebrafish. (A) Representative micrographs of liver microsections demonstrating that zebrafish alterations in liver fat content depend on the extract consumed, as visualized by Oil Red $\mathrm{O}$ and hematoxylin staining. (B) Oxidized species content, expressed as malondialdehyde (MDA) quantity, in liver tissues after homogenization. Data are shown as the mean of three independent measurements with duplicate samples. (C) Equal dilutions $(1.4 \mathrm{mg} / \mathrm{ml})$ of homogenized hepatic tissue (50 $\mu \mathrm{g}$ of liver in $0.5 \mathrm{ml}$ of PBS) from each group were used as antioxidant sources. Data are shown as the mean of three independent measurements with duplicate samples.

group 2. This in vivo observation is in good agreement with results from in vitro assays (Fig. 6), in which the extract of acai showed the strongest inhibitory ability for human CETP, while the extract of GS did not.
Hepatic tissue analysis. Histological analyses of hepatic tissue showed that zebrafish fed a normal diet exhibited normal, non-pathological histochemical features (Fig. 7). However, severe manifestations of fatty liver were observed 
in HCD-consuming fish; neutral lipid content, visualized as red color, was augmented, and severe infiltration of inflammatory cells was illuminated by the hematoxylin counterstaining. Among the extract-fed groups, those fed LL or acai demonstrated decreases in inflammatory cells and reduced intensity of Oil Red $\mathrm{O}$ staining, suggesting a reduction in hepatic fat storage and less inflammation. However, the GS-fed group showed a mild increase in fatty liver with darker-red staining intensity and a visible increase in inflammatory cell numbers.

Malondialdehyde (MDA) levels in hepatic tissue were 4-fold increased in the HCD group compared to those fed a normal diet, suggesting that high cholesterol consumption induced production of oxidized species (Fig. 7B). However, LL- and acai-fed groups had diminished MDA levels, in agreement with histological analyses demonstrating reduced infiltration of inflammatory cells (Fig. 7A). MDA levels and Oil Red O staining intensity were directly correlated.

FRA assays with hepatic homogenate showed the highest antioxidant potential in the ND-fed group, with an increase of 53\% from initial levels; the HCD-fed group showed a $9 \%$ increase in antioxidant capacity. Among the experimental groups, the group fed GS demonstrated the strongest FRA, at approximately $32 \%$ above initial levels, while acai- and LL-fed groups showed 16 and $23 \%$ increases, respectively.

In conclusion, LL, GS, and acai extracts shared antioxidant, anti-inflammatory, and anti-atherosclerotic abilities in a cellular model and in hypercholesterolemic zebrafish, although there is incomplete overlap of beneficial activities. These results can be applied to the development of functional foods incorporating these ingredients that can alleviate symptoms and pathology of chronic metabolic diseases such as cardiovascular disease or diabetes.

\section{Acknowledgements}

We thank Jung-Heun Park for her technical assistance. This study was supported by funding (no. 70004935) from the Ministry of Knowledge and Economy of the Republic of Korea.

\section{References}

1. Bantle JP: Dietary fructose and metabolic syndrome and diabetes. J Nutr 139: S1263-S1268, 2009.

2. Ito H, Kobayashi E, Takamatsu Y, et al: Polyphenols from Eriobotrya japonica and their cytotoxicity against human oral tumor cell lines. Chem Pharm Bull (Tokyo) 48: 687-693, 2000.

3. De Tommasi N, De Simone F, Cirino G, Cicala C and Pizza C: Hypoglycemic effects of sesquiterpene glycosides and polyhydroxylated triterpenoids of Eriobotrya japonica. Planta Med 57: 414-416, 1991.

4. Alshaker HA, Qinna NA, Qadan F, Bustami M and Matalka KZ: Eriobotrya japonica hydrophilic extract modulates cytokines in normal tissues, in the tumor of Meth-A-fibrosarcoma bearing mice, and enhances their survival time. BMC Complement Altern Med 11: 9, 2011

5. Zhou C, Sun C, Chen K and Li X: Flavonoids, phenolics, and antioxidant capacity in the flower of Eriobotrya japonica Lindl. Int J Mol Sci 12: 2935-2945, 2011.

6. Muramoto K, Quan RD, Namba T, et al: Ameliorative effects of Eriobotrya japonica seed extract on cellular aging in cultured rat fibroblasts. J Nat Med 65: 254-261, 2011.
7. Schauss AG, Wu X, Prior RL, et al: Phytochemical and nutrient composition of the freeze-dried amazonian palm berry, Euterpe oleracea mart. (acai). J Agric Food Chem 54: 8598-8603, 2006.

8. Xie C, Kang J, Burris R, et al: Acai juice attenuates atherosclerosis in ApoE deficient mice through antioxidant and anti-inflammatory activities. Atherosclerosis 216: 327-333, 2011.

9. Del Pozo-Insfran D, Percival SS and Talcott ST: Acai (Euterpe oleracea Mart.) polyphenolics in their glycoside and aglycone forms induce apoptosis of HL-60 leukemia cells. J Agric Food Chem 54: 1222-1229, 2006

10. Holderness J, Schepetkin IA, Freedman B, et al: Polysaccharides isolated from Açaí fruit induce innate immune responses. PLoS One 6: e17301, 2011.

11. Ribeiro JC, Antunes LM, Aissa AF, et al: Evaluation of the genotoxic and antigenotoxic effects after acute and subacute treatments with acai pulp (Euterpe oleracea Mart.) on mice using the erythrocytes micronucleus test and the comet assay. Mutat Res 695: 22-28, 2010.

12. Hogan S, Canning C, Sun S, Sun X, Kadouh H and Zhou K: Dietary supplementation of grape skin extract improves glycemia and inflammation in diet-induced obese mice fed a western high fat diet. J Agric Food Chem 59: 3035-3041, 2011.

13. Louli V, Ragoussis N and Magoulas K: Recovery of phenolic antioxidants from wine industry by-products. Bioresour Technol 92: 201-208, 2004.

14. Shi J, Yu J, Pohorly JE and Kakuda Y: Polyphenolics in grape seeds-biochemistry and functionality. J Med Food 6: 291-299, 2003.

15. Zhang FL, Gao HQ and Shen L: Inhibitory effect of GSPE on RAGE expression induced by advanced glycation end products in endothelial cells. J Cardiovasc Pharmacol 50: 434-440, 2007.

16. Bertelli AA and Das DK: Grapes, wines, resveratrol, and heart health. J Cardiovasc Pharmacol 54: 468-476, 2009.

17. Waterhouse AL: Wine phenolics. Ann NY Acad Sci 957: 21-36, 2002.

18. Ndiaye M, Philippe C, Mukhtar $\mathrm{H}$ and Ahmad N: The grape antioxidant resveratrol for skin disorders: promise, prospects, and challenges. Arch Biochem Biophys 508: 164-170, 2011.

19. Stoletov K, Fang L, Choi SH, et al: Vascular lipid accumulation, lipoprotein oxidation, and macrophage lipid uptake in hypercholesterolemic zebrafish. Circ Res 104: 952-960, 2009.

20. Jin S, Hong JH, Jung SH and Cho KH: Turmeric and laurel aqueous extracts exhibit in vitro anti-atherosclerotic activity and in vivo hypolipidemic effects in a zebrafish model. J Med Food 14: 247-256, 2011.

21. Jin S and Cho KH: Water extracts of cinnamon and clove exhibits potent inhibition of protein glycation and anti-atherosclerotic activity in vitro and in vivo hypolipidemic activity in zebrafish. Food Chem Toxicol 49: 1521-1529, 2011.

22. Singleton VL and Rossi JA Jr: Colorimetry of total phenolics with phenolics with phosphomolybdic-phosphotungstic acid reagents. Am J Enol Vitic 16: 144-158, 1965.

23. Meda A, Lamien CE, Romito M, Millogo J and Nacoulma OG: Determination of the total phenolic, flavonoid and proline contents in Burkina fasan honey, as well as their radical scavenging activity. Food Chem 91: 571-577, 2005.

24. Wrolstad RE, Durst RW and Lee J: Tracking color and pigment changes in anthocyanin products. Trends Food Sci Technol 16: 423-428, 2005.

25. Jurd L and Asen S: The formation of metal and co-pigment complexes of cyaniding-3-glucoside. Phytochemistry 5: 1263-1271, 1966.

26. Benzie IF and Strain JJ: The ferric reducing ability of plasma (FRAP) as a measure of 'antioxidant power': the FRAP assay. Anal Biochem 239: 70-76, 1996.

27. Park KH, Kim JR, Lee JS, Lee $\mathrm{H}$ and Cho KH: Ethanol or water extract of purple sweet potato exhibits anti-atherosclerotic activity and inhibitory activity against protein glycation. J Med Food 13: 91-98, 2010.

28. Esterbauer H, Striegl G, Puhl H and Rotheneder M: Continuous monitoring of in vitro oxidation of human low density lipoprotein. Free Radic Res Commun 6: 67-75, 1989.

29. Noble RP: Electrophoretic separation of plasma lipoproteins in agarose gel. J Lipid Res 9: 693-700, 1968.

30. Brewer HB Jr, Ronan R, Meng M and Bishop C: Isolation and characterization of apolipoprotein A-I, A-II, and A-IV. Methods Enzymol 128: 223-246, 1986. 
31. McPherson JD, Shilton BH and Walton DJ: Role of fructose in glycation and cross-linking of proteins. Biochemistry 27: 1901-1907, 1988.

32. Park KH, Jang WJ, Kim KY, Kim JR and Cho KH: Fructated apolipoprotein A-I showed severe structural modification and loss of beneficial functions in lipid-free and lipid-bound state with acceleration of atherosclerosis and senescence. Biochem Biophys Res Commun 392: 295-300, 2010.

33. Park KH and Cho KH: High-density lipoprotein (HDL) from elderly and reconstituted HDL containing glycated apolipoproteins A-I share proatherosclerotic and prosenescent properties with increased cholesterol influx. J Gerontol A Biol Sci Med Sci 66: 511-520, 2011.

34. Cho KH: Synthesis of reconstituted high-density lipoprotein (rHDL) containing apoA-I and apoC-III: the functional role of apoC-III in rHDL. Mol Cells 27: 291-297, 2009.

35. Havel RJ, Eder HA and Bragdon JH: The distribution and chemical composition of ultracentrifugally separated lipoproteins in human serum. J Clin Invest 34: 1345-1353, 1955.
36. Blois MS: Antioxidant determinations by the use of a stable free radical. Nature 181: 1199-1200, 1958.

37. Fraenkel-Conrat $\mathrm{H}$ : Methods for investigating the essential groups for enzyme activity. Methods Enzymol 4: 247-269, 1957.

38. Choi JE, Kim S, Ahn JH, et al: Induction of oxidative stress and apoptosis by silver nanoparticles in the liver of adult zebrafish. Aquat Toxicol 100: 151-159, 2010.

39. Schaefer EJ and Asztalos BF: Cholesteryl ester transfer protein inhibition, high-density lipoprotein metabolism and heart disease risk reduction. Curr Opin Lipidol 17: 394-398, 2006.

40. Brousseau ME: Emerging role of high-density lipoprotein in the prevention of cardiovascular disease. Drug Discov Today 10: 1095-1101, 2005

41. Cho KH, Hong JH and Lee KT: Monoacylglycerol (MAG)-oleic acid has stronger antioxidant, anti-atherosclerotic, and protein glycation inhibitory activities than MAG-palmitic acid. J Med Food 13: 99-107, 2010. 